\title{
Corrigendum
}

\section{Crying Without a Cause and Being Easily Upset in Two-Year-Olds: Heritability and Predictive Power of Behavioral Problems - Corrigendum}

Maria M. Groen-Blokhuis, Christel M. Middeldorp, Catharina E. M. van Beijsterveldt, and Dorret I. Boomsma

doi: http://dx.doi.org/10.1375/twin.14.5.393, Published by Australian Academic Press 2011.

On page 399 Figure 2 should be as follows:

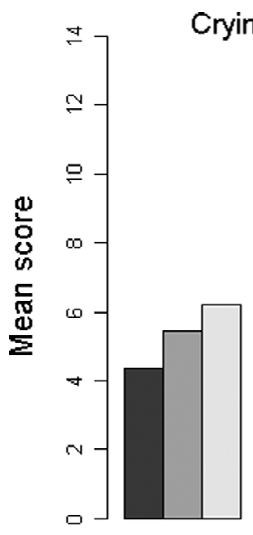

Int

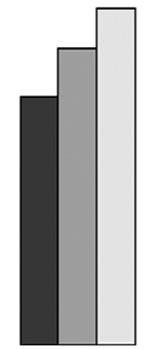

Ext

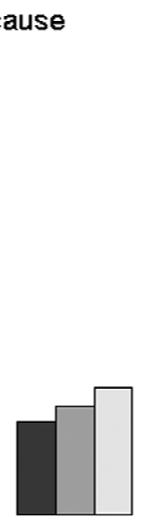

Att

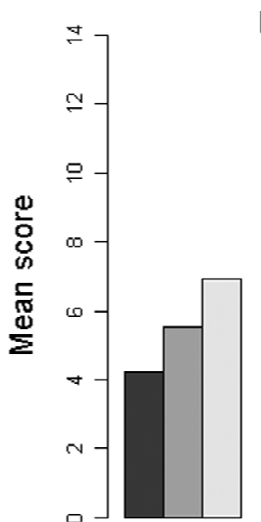

Int
Easily upset

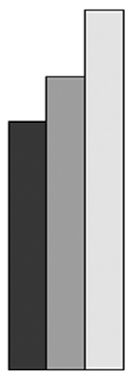

Ext

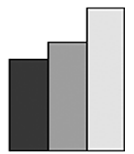

Att

- Rarely

- Sometimes

Often

- Neverihardly ever

- A bit

Yes

\section{Reference}

Groen-Blokhuis, M. M., Middeldorp, C. M., van Beijsterveldt, C. E. M., \& Boomsma, D. I. (2011). Crying without a cause and being easily upset in two-year-olds: Heritability and predictive power of behavioral problems. Twin Research and Human Genetics, 14, 393-400. 